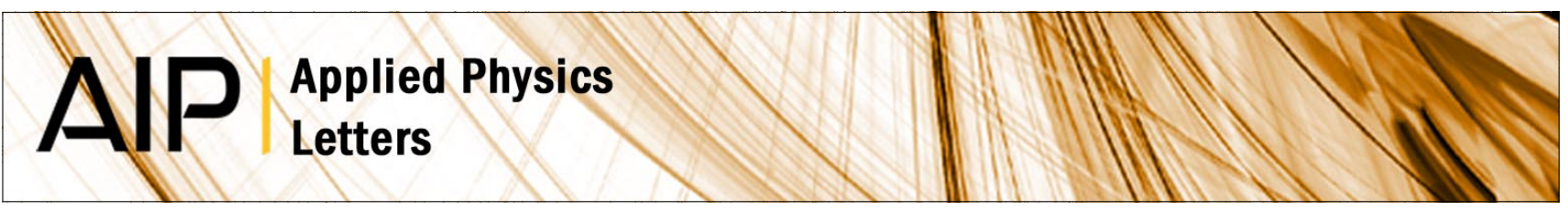

\title{
High-sensitivity, high-selectivity detection of chemical warfare agents
}

Michael B. Pushkarsky, Michael E. Webber, Tyson Macdonald, and C. Kumar Patel

Citation: Appl. Phys. Lett. 88, 044103 (2006); doi: 10.1063/1.2166692

View online: http://dx.doi.org/10.1063/1.2166692

View Table of Contents: http://apl.aip.org/resource/1/APPLAB/v88/i4

Published by the American Institute of Physics.

Additional information on Appl. Phys. Lett.

Journal Homepage: http://apl.aip.org/

Journal Information: http://apl.aip.org/about/about_the_journal

Top downloads: http://apl.aip.org/features/most_downloaded

Information for Authors: http://apl.aip.org/authors

\section{ADVERTISEMENT}

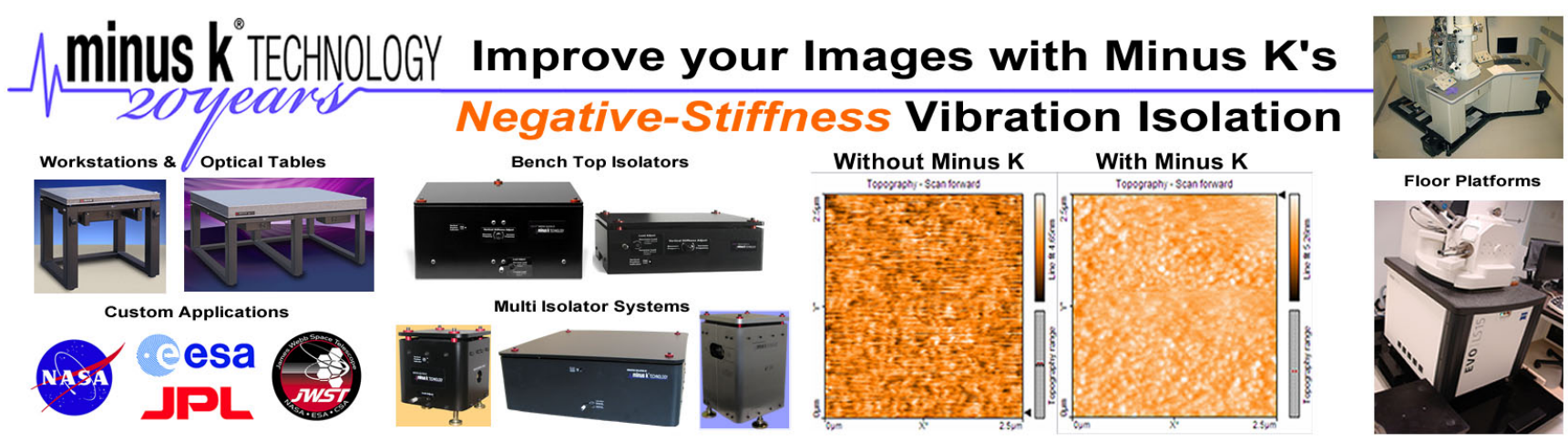




\title{
High-sensitivity, high-selectivity detection of chemical warfare agents
}

\author{
Michael B. Pushkarsky, Michael E. Webber, ${ }^{\text {a) }}$ and Tyson Macdonald \\ Pranalytica, Inc., 1101 Colorado Avenue, Santa Monica, California 90401 \\ C. Kumar N. Patel ${ }^{\text {b) }}$ \\ Pranalytica Inc., 1101 Colorado Avenue, Santa Monica, California 90401 \\ and Department of Physics \& Astronomy, University of California, Los Angeles, California 90095
}

(Received 16 May 2005; accepted 30 November 2005; published online 27 January 2006)

\begin{abstract}
We report high-sensitivity detection of chemical warfare agents (nerve gases) with very low probability of false positives (PFP). We demonstrate a detection threshold of $1.2 \mathrm{ppb}\left(7.7 \mu \mathrm{g} / \mathrm{m}^{3}\right.$ equivalent of Sarin) with a PFP of $<1: 10^{6}$ in the presence of many interfering gases present in an urban environment through the detection of diisopropyl methylphosphonate, an accepted relatively harmless surrogate for the nerve agents. For the current measurement time of $\sim 60 \mathrm{~s}$, a PFP of $1: 10^{6}$ corresponds to one false alarm approximately every 23 months. The demonstrated performance satisfies most current homeland and military security requirements. (c) 2006 American Institute of Physics. [DOI: 10.1063/1.2166692]
\end{abstract}

Optical spectroscopy has long been used for identifying chemical compounds and is a relevant technique because the CWAs have strong optical absorption features in the infrared in the $9-11.5 \mu \mathrm{m}$ region (Fig. 1, top panel), with absorption strengths $^{1}$ of $(1-6) \times 10^{-3}$ (ppm meter $)^{-1}$. Detection of these gases at ppb levels of interest will necessitate absorption coefficient measurements of $(1-6) \times 10^{-8} \mathrm{~cm}^{-1}$. Laser photoacoustic spectroscopy (L-PAS) permits such measurements in short optical pathlengths. ${ }^{2-4}$ Because high-power $(>1 \mathrm{~W})$ $\mathrm{CO}_{2}$ lasers are available with wide tunability (Fig. 1, bottom panel) throughout the 9-11.5 $\mu \mathrm{m}$ where the CWAs absorb, they are ideal laser sources for L-PAS systems for the detection of the CWAs.

For the detection the CWAs in real environments, however, high sensitivity alone is not sufficient. Sensor must have very few false alarms to avoid unacceptable social and economic disruptions. The problem of interference rejection is severe because the broad absorption features of many interferents ${ }^{5}$ overlap with the broad absorption features of the target CWA. In normal indoor or outdoor environments, hundreds of gases are present, of which a few dozen need special consideration because of their ambient concentrations, absorption magnitudes, and spectral overlap with the CWAs. A simulation model has shown ${ }^{5}$ that L-PAS in this wavelength region could detect the CWAs at very low concentrations with very low PFP by using multiple wavelengths of the $\mathrm{CO}_{2}$ laser to map the spectral signature of the target gas in a "soup" of background species.

Principles of L-PAS have been described in many papers. Our photoacoustic spectrometer ${ }^{6}$ includes a ${ }^{13} \mathrm{CO}_{2}$ laser that is tuned across 34 laser transitions in the $\mathrm{P}$ and $\mathrm{R}$ branches of the $00^{0} 1-\left[10^{0} 0,02^{0} 0\right]_{\|}$, band, covering 9.6 to $10.2 \mu \mathrm{m}$ in $\sim 40$ seconds. The normalized PA on a laser transition is proportional to the cumulative optical absorption caused by all of the gases present in the cell including CWAs. The individual contribution from CWAs and the

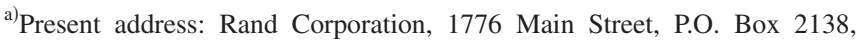
Santa Monica, CA 90407.

${ }^{\text {b) }}$ Author to whom correspondence should be addressed; electronic mail: patel@pranalytica.com)
}

other species is extracted using the spectral libraries recorded with the spectrometer and a linear pattern recognition ${ }^{5}$ algorithm embedded in the analyzer. Diisopropyl methylphosphate (DIMP), an accepted and a relatively harmless surrogate for CWAs, was used to demonstrate the performance of the L-PAS for CWA detection.

Figure 2 shows the spectral libraries used to evaluate $\alpha_{i, \lambda_{j}}$, the absorption coefficient of species $i$ at wavelength $\lambda_{j}$. Three additional vectors were added to account for the offset, slope, and curve of the background signals. When a mixture of trace gases is present in the photoacoustic cell, the total absorption $\alpha_{\lambda_{j}}$ at a specific wavelength $\lambda_{j}$ is given by

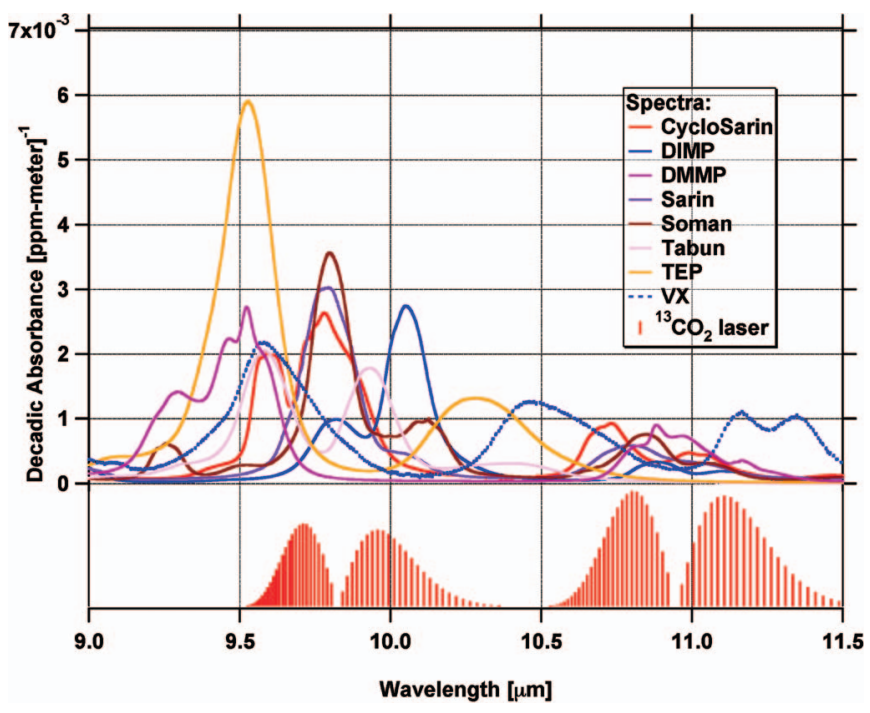

FIG. 1. (Color) Spectral absorption features of Tabun (GA), Sarin (GB), Soman (GD), Cyclosarin (GF), VX, triethyl phosphate (TEP), dimethyl methylphosphonate (DMMP), and diisopropyl methylphosphonate (DIMP) in the 9-11.5 $\mu \mathrm{m}$ region (top panel); positions and relative power levels of the ${ }^{13} \mathrm{CO}_{2}$ laser output on the lasing transitions as a function of the wavelength (bottom panel). The left group of transitions corresponding to the $\mathrm{P}$ and $\mathrm{R}$ branches of the $00^{0} 1-\left[10^{0} 0,02^{0} 0\right]_{\|}$band are used in the present studies to evaluate the performance of the L-PAS spectrometer for the detection of CWAs. 

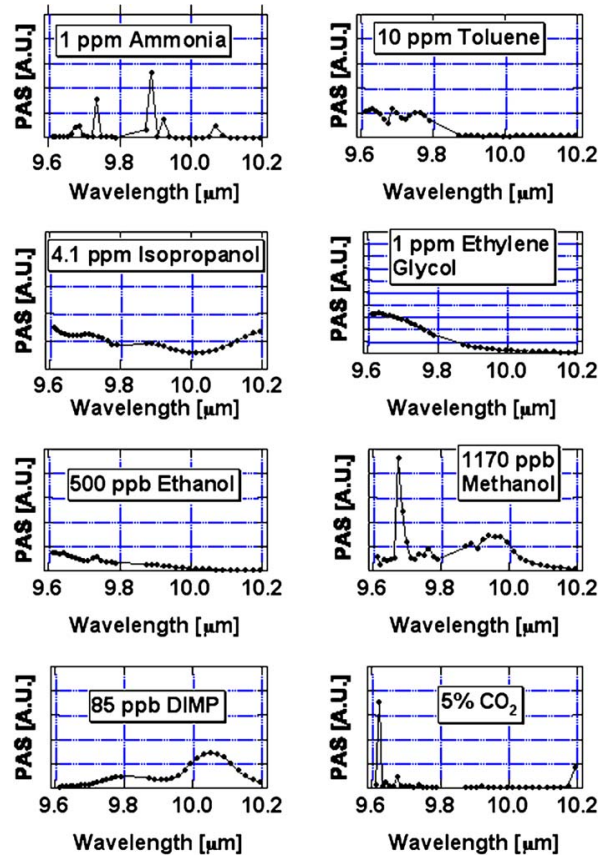

FIG. 2. Measured photoacoustic absorption spectra for ammonia, toluene, isopropanol, ethylene, ethanol, methanol, DIMP, and $\mathrm{CO}_{2}$. Dots represent measured PAS signals at the peak of the ${ }^{13} \mathrm{CO}_{2}$ laser lines.

$$
\begin{aligned}
\text { Absorption Coefficient }\left.\right|_{\lambda_{j}}=\alpha_{\lambda_{j}}=\sum_{i=1}^{\text {\# of species }} \alpha_{i, \lambda_{j}} \\
=\sum_{i=1}^{\# \text { of species }} \sigma_{i, \lambda_{j}} X_{i},
\end{aligned}
$$

where $\sigma_{i, \lambda_{j}}$ is the absorbance for species $i$ at wavelength $\lambda_{j}$, and $X_{i}$ is the mole fraction of the species $i$. The measured signal is linear for over five orders of magnitude until the

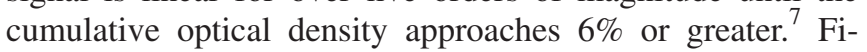
nally, from the measured absorption strength matrix $\alpha_{i, \lambda_{j}}$, we derive concentration of the specific component. ${ }^{5}$

L-PAS analyzer performance to measure DIMP was evaluated in the presence of eight species listed in Table I that were determined in the simulations to be the worst expected interferents. ${ }^{5}$ Analyzer performance is a combination

TABLE I. Components and concentrations used in the present study for synthetic clean air, outdoor Santa Monica air, and synthetic contaminated air.

\begin{tabular}{llll}
\hline \hline Component & $\begin{array}{l}\text { Concentrations } \\
\text { for synthetic } \\
\text { clean air }\end{array}$ & $\begin{array}{l}\text { Concentrations } \\
\text { for Santa } \\
\text { Monica air }\end{array}$ & $\begin{array}{l}\text { Concentrations } \\
\text { for synthetic } \\
\text { contaminated air }\end{array}$ \\
\hline Nitrogen & $79 \%$ & $79 \%$ & $79 \%$ \\
Oxygen & $20 \%$ & $20 \%$ & $20 \%$ \\
Water & $1 \%$ & $1 \%-2 \%$ & $1 \%$ \\
Carbon dioxide & $500 \mathrm{ppm}$ & $300-550 \mathrm{ppm}$ & $500 \mathrm{ppm}$ \\
n-propanol & None & Unknown & $730 \mathrm{ppb}$ \\
Ethylene Glycol & None & Unknown & $360 \mathrm{ppb}$ \\
Toluene & None & Unknown & $3.6 \mathrm{ppm}$ \\
Methanol & None & Unknown & $830 \mathrm{ppb}$ \\
Ammonia & None & Unknown & $700 \mathrm{ppb}$ \\
Ethanol & None & Unknown & $330 \mathrm{ppb}$ \\
All others & None & Unknown & None \\
\hline \hline
\end{tabular}

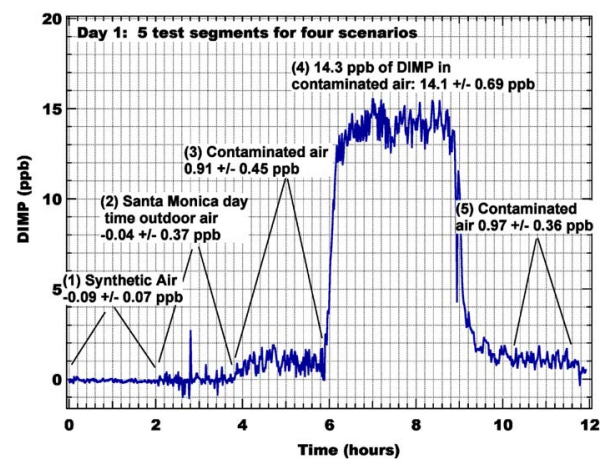

FIG. 3. L-PAS analyzer measurements of DIMP in 5 segments: (1) synthetic clean air, (2) Santa Monica city street air, (3) synthetic contaminated air with no DIMP, (4) synthetic contaminated air with 14.3 ppb DIMP present, and (5) synthetic contaminated air with no DIMP.

of sensitivity, accuracy, and selectivity (low false alarms when the target gas is not present). Four different measurement scenarios were used:

(1) 0 ppb DIMP in synthetic clean air to determine best-case sensitivity,

(2) 0 ppb DIMP in real outdoor Santa Monica air to establish a benchmark for sensitivity and selectivity in nominal urban conditions,

(3) 0 ppb DIMP in synthetic, highly contaminated air to establish sensitivity and selectivity under extreme conditions,

(4) $14.3 \mathrm{ppb}$ DIMP in synthetic contaminated air to establish accuracy.

The results of these four test cases are plotted in Fig. 3 with five different test segments (case 3 is conducted twice), and summarized in Table II. Case 1 is used to establish a benchmark for sensitivity with synthetic clean air $\left(\mathrm{O}_{2}, \mathrm{~N}_{2}\right.$, $1 \% \mathrm{H}_{2} \mathrm{O}, 500 \mathrm{ppm} \mathrm{CO}_{2}$ ) and no DIMP present; the analyzer produced an average DIMP reading of $-0.09 \pm 0.07 \mathrm{ppb}(1 \sigma)$ over 120 successive measurements (Fig. 3, segment 1). Thus, the best-case sensitivity for the system is approximately $70 \mathrm{ppt}\left(0.51 \mu \mathrm{g} / \mathrm{m}^{3}\right)$ and the zero-level is within $100 \mathrm{ppt}$ of true zero.

Testing the L-PAS under nominal urban contamination levels was achieved in case 2 by measuring daytime outdoor Santa Monica air with no DIMP present (see Table I ). For this test (Fig. 3, segment 2) 110 successive measurements yielded an average DIMP reading of $-0.04 \pm 0.37 \mathrm{ppb}$ corresponding to a sensitivity of $2.7 \mu \mathrm{g} / \mathrm{m}^{3}$. The cumulative effect of the interferences is a degradation of the sensitivity by a factor of $\sim 6$, but with no effect on the zero level, which remained within $100 \mathrm{ppt}$ of true zero.

TABLE II. Measurement results for each test segment.

\begin{tabular}{clll}
\hline \hline Segment & Test Conditions & $\begin{array}{l}\text { Actual DIMP } \\
\text { concentration }\end{array}$ & $\begin{array}{l}\text { Measured DIMP } \\
\text { concentration }\end{array}$ \\
\hline (1) & Synthetic clean air & $0 \mathrm{ppb}$ & $-0.09 \pm 0.07 \mathrm{ppb}$ \\
(2) & $\begin{array}{l}\text { Santa Monica outdoor air } \\
\text { (daytime) }\end{array}$ & $0 \mathrm{ppb}$ & $-0.04 \pm 0.37 \mathrm{ppb}$ \\
& & \\
(3) & Synthetic contaminated air & $0 \mathrm{ppb}$ & $0.91 \pm 0.45 \mathrm{ppb}$ \\
(4) & Synthetic contaminated air & $14.3 \mathrm{ppb}$ & $14.1 \pm 0.69 \mathrm{ppb}$ \\
(5) & Synthetic contaminated air & $0 \mathrm{ppb}$ & $0.97 \pm 0.36 \mathrm{ppb}$ \\
\hline \hline
\end{tabular}




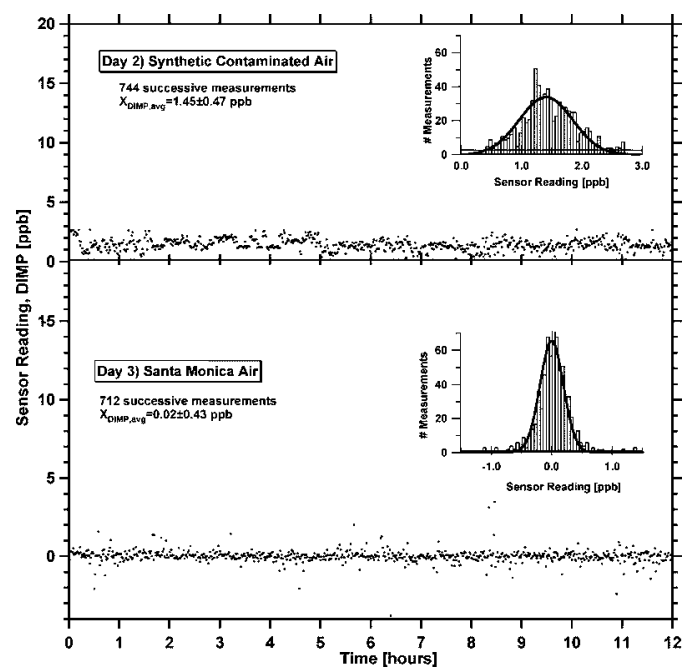

FIG. 4. Measurements of DIMP in synthetic contaminated air and Santa Monica air over $12 \mathrm{~h}$ on different days to determine the sensitivity and PFP. Histograms for both days are shown as insets, with Gaussian curve fits used to estimate PFP. For example, for the situation represented in the top panel for highly contaminated synthetic ambient air, PFP for a detection (alarm) threshold of $2 \mathrm{ppb}$ is calculated by taking the ratio of the area under the histogram for sensor reading $>2 \mathrm{ppb}$ and the total area under the histogram. For a $2 \mathrm{ppb}$ alarm threshold, this situation yields an unacceptable level of PFP of about $10 \%$. Increasing the threshold to $3.5 \mathrm{ppb}$ lowers the PFP to an acceptable $10^{-6}$.

A performance test in highly contaminated conditions was conducted by analyzing a synthetic air mixture shown in Table I, the components of which are expected to be significant interferences. ${ }^{5}$ The concentration for each species was picked to be at levels exceeding those expected to be found in indoor contaminated air to serve as a strict test. The results, shown in the segments 3 and 5 (Fig. 3) reveal that the interferences cause the zero-level increase to an average reading of 0.91 and $0.97 \mathrm{ppb}$ DIMP for the two respective segments, and degrade the $1 \sigma$ precision to 0.45 and $0.36 \mathrm{ppb}$ (3.3 and $2.7 \mu \mathrm{g} / \mathrm{m}^{3}$ ), respectively. For reference, a typical CWA (Sarin) exposure that causes the first noticeable health effect $\left(\right.$ miosis $\left.^{8}\right)$ is $1 \mathrm{mg} \cdot \mathrm{min} / \mathrm{m}^{3}$; that is, a permissible concentration $^{9-11}$ of about $33 \mu \mathrm{g} / \mathrm{m}^{3}$ (5.8 ppb) for an exposure of $30 \mathrm{~min}$, and $16 \mu \mathrm{g} / \mathrm{m}^{3}$ (2.9 ppb) for an exposure of $60 \mathrm{~min}$. The L-PAS accuracy in the presence of interferences

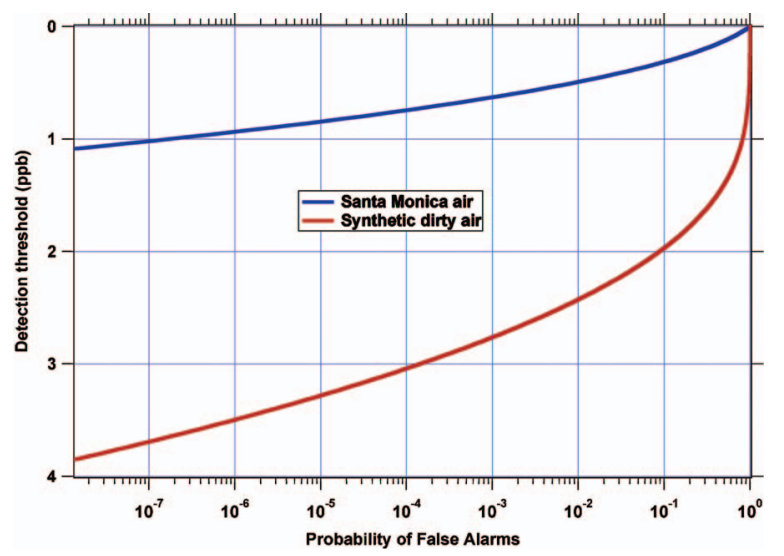

FIG. 5. (Color) Measured receiver operation characteristic curve for the detection of DIMP, an accepted surrogate for Sarin, in the presence of Santa Monica street air and synthetic dirty air. was established by adding 14.3 ppb DIMP to the synthetic contaminated air mixture. The L-PAS gave an average reading of $14.1 \pm 0.69 \mathrm{ppb}$ (Fig. 3, segment 4), yielding excellent accuracy and a precision.

The experimental data for apparent DIMP values when it is not present permit us to estimate PFP for a particular alarm threshold. The PFP is the number of times the sensor indicates that DIMP is present above the alarm threshold even when no DIMP is present. The PFP is evaluated using the statistical noise characteristics of the observed "zero DIMP" signal. $^{5}$ The statistical variation of sensor readings over $12 \mathrm{~h}$ of measurements for the cases 2 and 3 are shown in Fig. 4. The average of sensor readings for synthetic contaminated air over the $12 \mathrm{~h}$ period on day 2 and for Santa Monica outdoor air over the $12 \mathrm{~h}$ period on day 3 were $1.45 \pm 0.47 \mathrm{ppb}$ (the offset is the result of interferences, rather than from residual DIMP) and $0.02 \pm 0.43 \mathrm{ppb}$, respectively.

Histograms for each of the two cases, with $>700$ data points, are shown as insets. The PFP is calculated by performing a Gaussian fit to the histograms and then comparing the area under the curve above the alarm level with the total area under the curve. Figure 5 shows a plot of alarm threshold versus PFP (receiver operation characteristic, ROC) evaluated from the data in Fig. 4. For synthetic contaminated air, a false alarm will occur once every million measurements for an alarm threshold of $3.5 \mathrm{ppb}\left(20 \mu \mathrm{g} / \mathrm{m}^{3}\right.$ equivalent of Sarin), while for Santa Monica outdoor air the results are much better, and a PFP of $1: 10^{6}$ is achieved with a lower threshold of $0.95 \mathrm{ppb}\left(6.1 \mu \mathrm{g} / \mathrm{m}^{3}\right.$ equivalent of Sarin). A PFP of $1: 10^{6}$ leads to one false alarm every $\sim 23$ months (measurement time of $1 \mathrm{~min}$ ). Both alarm settings are lower than the $30 \mathrm{~min}$ exposure threshold for miosis $\left(33 \mu \mathrm{g} / \mathrm{m}^{3}\right.$ or $5.8 \mathrm{ppb}$ ), and are satisfactory for the $60 \mathrm{~min}$ threshold $\left(16 \mu \mathrm{g} / \mathrm{m}^{3}\right.$ or $\left.2.9 \mathrm{ppb}\right)$ and should be adequate for warning the population at large about a CWA attack. It should be noted that the ROC curves (Fig. 5) permit a user to optimize the alarm threshold and the PFP depending on specific applications.

This work was supported, in part, through a DARPA contract MDA972-02-C-0092 (Approved for Public Release, Distribution Unlimited).

${ }^{1}$ S. W. Sharpe, R. L. Sams, T. J. Johnson, P. M. Chu, G. C. Rhoderick, and F. R. Guenther, Proc. SPIE 4577, 12 (2001).

${ }^{2}$ L. B. Kreuzer, J. Appl. Phys. 42, 2934 (1971).

${ }^{3}$ Topics in Current Physics: Photoacoustic, Photothermal and Photochemical Processes in Gases, edited by P. Hess (Springer, Berlin, 1989).

${ }^{4}$ M. B. Pushkarsky, M. E. Webber, and C. K. N. Patel, Appl. Phys. B: Lasers Opt. 77, 381 (2003).

${ }^{5}$ M. E. Webber, M. B. Pushkarsky, and C. K. N. Patel, J. Appl. Phys. 97, 113101 (2005).

${ }^{6}$ M. B. Pushkarsky, M. E. Webber, T. N. Macdonald, and C. K. N. Patel (unpublished).

${ }^{7}$ A. Schmohl, A. Miklos, and P. Hess, Appl. Opt. 41, 1815 (2002).

${ }^{8}$ The first noticeable health effect is miosis, which for Sarin includes pinpointing of the pupil of the eye accompanied by runny nose, tightness of the chest, and eye pain.

${ }^{9}$ Department of the Army, Army Field Manual No. 3-9; Potential Military Chemical/Biological Agents and Compounds (Headquarters of the Army, Washington, D.C., 1990), pp. 19-20.

${ }^{10}$ B. McNamara and L. Leitnaker, Edgewood Arsenal Special Publication (U.S. Army, Medical Research Laboratories, Edgewood Arsenal, Aberdeen Proving Grounds, MD, 1971).

${ }^{11}$ Department of Health and Human Services, Center for Disease Control, Federal Register 53, 8504 (1988). 